Canadian University Music Review

Revue de musique des universités canadiennes

\title{
The Construction of Music as a Social Phenomenon: Implications for Deconstruction
}

\section{Line Grenier}

Volume 10, numéro 2, 1990

Alternative Musicologies

Les Musicologies Alternatives

URI : https://id.erudit.org/iderudit/1014884ar

DOI : https://doi.org/10.7202/1014884ar

Aller au sommaire du numéro

Éditeur(s)

Canadian University Music Society / Société de musique des universités

canadiennes

ISSN

0710-0353 (imprimé)

2291-2436 (numérique)

Découvrir la revue

Citer cet article

Grenier, L. (1990). The Construction of Music as a Social Phenomenon:

Implications for Deconstruction. Canadian University Music Review / Revue de

musique des universités canadiennes, 10(2), 27-47.

https://doi.org/10.7202/1014884ar

All Rights Reserved @ Canadian University Music Society / Société de musique des universités canadiennes, 1990
Ce document est protégé par la loi sur le droit d'auteur. L'utilisation des services d'Érudit (y compris la reproduction) est assujettie à sa politique d'utilisation que vous pouvez consulter en ligne.

https://apropos.erudit.org/fr/usagers/politique-dutilisation/ 


\section{THE CONSTRUCTION OF MUSIC AS A SOCIAL PHENOMENON: IMPLICATIONS FOR DECONSTRUCTION}

\section{Line Grenier}

\section{PRELIMINARY REMARKS}

Over the past decades, there has been a growing acknowledgement of the social character of music, an acknowledgement which has led researchers from various disciplines to pay closer attention to the work and findings of social scientists. As a result, many researchers have also come to urge the necessity of a multidisciplinary approach to music, recognizing that far from leading to a purely reductionist approach, the social sciences could contribute significantly to renewed and extended musical studies. In this context, sociology is often pointed to as one of the disciplines which could play an important if not decisive role in this joint venture. But what could or should be sociology's most fruitful role?

Without underestimating the valuable and necessary empirical work that has been (and still will be) undertaken, one of the most original and significant contributions sociology could make is of a theoretical nature. In my opinion, it should consist in bringing forth a definition of music as a fully-fledged social phenomenon, one that would not only grasp its constitutive social dimensions, its various historical forms and foundations, but also recognize and account for its very specificity.

Some steps have recently been taken in this direction. However, to my knowledge, there is as yet no fully developed conceptual framework which lives up to these two requirements. This does not imply that autonomous views - according to which music is conceived as a self-contained phenomenon, totally independent of social, psychological and historical realities - still prevail. It means that to a large extent music is still granted only a limited or partial social character, and allowed only a mere aesthetic or artistic specificity.

Under these conditions, deconstruction appears as an absolute prerequisite to any theoretical inquiry. I would like to contribute to what I consider to be a 
"constructive process of deconstruction" by disclosing the limits of today's most predominant theoretical frameworks which, despite the fact that they convey divergent concepts of music, fail to theorise music as a fully-fledged and specifically social phenomenon.

\section{"MUSIC": A SINGLE TERM CONNOTING DISTINCT CONCEPTS}

Perhaps more than before, music is the object of a wide range of theories which sometimes complement but, more often, contradict each other. It is surely tempting to impute at least part of those discrepancies to the variety of disciplines involved. However, this would constitute far too reductionist or simplistic an explanation. For instance, how could it account for the fact that various contrasting approaches cross over disciplinary (as well as institutional) boundaries: or that theories issuing from diverse disciplinary locations share the same basic conception of music?

It seems more likely that most ambiguities can be ascribed not only to the highly polysemic nature of the term "music," but above all to the fact that the notion encompasses distinct concepts. Considering their current state of development, one can advantageously apply to the field of musical studies the results of Zygmunt Bauman's analysis of the notion of culture in the modern social sciences: "in each case the term, though keeping its form intact, connotes a different concept" (Bauman 1973: 6). I believe this is the prevailing situation in music: while talking about "music,"' researchers might be addressing very different issues! In my opinion, the notion of music is indeed related to heterogeneous semantic fields; it designates distinct observable phenomena and stands for diverse if not irreconcilable objects of research. More precisely, I would argue that it connotes three basic concepts, hereafter referred to as "conceptualized art," "cultural product" (or practice) and "symbolic system" (or phenomenon).

Taken as a whole, the field of contemporary theory on music can be said to form an axiomatic tripartite division within which each concept is embodied in a separate - almost exclusive - set of premises and assumptions. The very notion of music is thus part of three highly intricate categorial networks. In fact, these networks constitute different univers de discours of which the most discriminating parameter is, undoubtedly, their respective conceptualization of music with regard to its social character. Indeed - and I wish to emphasize this point as the prime concern of this critical account - the three concepts are best characterized and identified through the distinct views of the social nature of music they reveal. In the same order as above, these views can be qualified as "hierarchic," "differential" and "generic." Moreover, these three constructions of the social character of music refer to as many distinct ways of addressing the issue of the specificity of music. 
I would like to present briefly the main features of this tripartite division, emphasizing their respective theoretical implications with regard to the development of a definition of music as a specific and fully-fledged social phenomenon.

\section{A SCHEMATIC PORTRAIT OF CONTEMPORARY MUSICAL THEORIES}

\section{“Conceptualized Art”: From Description to Prescription}

The first concept of this tripartite division can be considered as the traditional view on music, not only because its origins can be traced back to Ancient Greece, but because it has for a long time exerted a quasi-monopoly on most academic and formally sanctioned conceptualizations of music. In words borrowed from Shepherd and Vulliamy, it could be described as "a conception of music equatable with musical notation" (1983: 3). Basically, it rests on the three following assumptions:

a) that music is the art of sounds, i.e., of combining sounds;

b) that it is an art which can be written and read according to a definite set of rules, i.e., those of so-called modern notation;

c) that one must concentrate on the score - the very physical mode of music's existence (Nattiez 1987) - as it presumably gives access to the essential and intrinsic components of music, thus enabling the identification and preservation of musical works.

There is neither the space nor the need to review here the various criticisms that have been lodged against this rather orthodox view over the years. However, one aspect of the discussion it still gives rise to is worth underlining: debates often take the form of an opposition between the eye (the score) and the ear (the sounding object). While those supporting this view claim that musical language - with the score as its concrete actualization - is the very essence of music, opponents argue it is an approach which distorts the true nature of music, which cannot be grasped outside the realm of its phenomenological sounding existence. But is not this eye/ear opposition an oversimplification of the issue? It seems too reductionist since it leaves aside the crucial role played by modern musical theory as a necessary mediation between the score and the sounding object. Therefore, I suggest we examine this approach from the point of view of its three constitutive components - notation, theory and score. It could be the key to a more accurate understanding of this concept, primarily in terms of its implications for the social status of music. 
Reduced to its simplest and most significant terms, this notation-oriented concept is a partial (e.g. biased and in-part) description of musical phenomena. If its value and usefulness are undeniable, its implications for Western musical life in general may be even greater. For it is but the historically located product of a rational process of objectification which, as it culminated in the development of modern notation, enabled the deconstruction of musical flow into parametric units (e.g. musical "notes"), thus providing discrete objects as the raw materials for mental cognition. Keeping in mind this fundamental historical and epistemological background, one cannot help but admit that the common assumption according to which musical signs correspond (more or less directly) to audible sounds, is incorrect. In fact, these signs correspond to the conceptualized sounds defined and encompassed by musical theory. In other words, notation is not a visual representation of "tangible" music; it constitutes the graphic translation of the conceptual representational system it stems from, that is modern Western (functional tonal) musical theory.

These conceptualized sounds represented by notation, as well as the rules for combining them provided by musical theory, were in fact derived from a process of acoustical objectification which led to the definition of sounds as physical objects on the one hand, and of musical sounds as acoustical objects on the other. According to this physical/musical parallel - a central feature of musical thinking since the Eighteenth and Nineteenth Centuries - one could determine the characteristics of musical sounds (namely pitch, intensity and timbre) from the physical properties of any vibrating body. Because of the overwhelming social power and epistemological pretentions of positivistic science, this acoustical conceptualisation of music has spread quickly; ever since, it has tended to be taken for granted as a "natural," "objective" reality. It is thought of as an irrefutable "truth," and unduly considered as such. I would argue that, in the same way that the notes used in the score relate to conceptualized non-audible sounds, "musical sounds" defined strictly according to physical properties do not designate music as perceived: they refer to a theoretical construct which is not the object of musical experience as such, but the object of acoustics.

In the light of an understanding of this process of double objectification (which helps to disentangle the various relations between notation, score and musical theory within the "conceptualized art" concept), it should be clear that this view not only possesses analytical and descriptive values: it combines normative and evaluative functions as well. A correlation of this view is the implicit assumption that it provides an absolute, unique and universal set of tools (both theoretically and methodologically) which could be fruitfully applied to any musical phenomenon, regardless of its social, cultural or historical context or setting. As Shepherd explains: "it is assumed 
that there are a fixed set of criteria against which all music can ultimately be judged" (1981: 121).

Overall, this approach not only leads to an objective aesthetic; it also conveys a hierarchic definition of music. It can be characterised as hierarchic in at least two respects. On the one hand, all existing musical works and practices end up being implicitly or explicitly rated; usually, the higher echelons of this scale are restricted to so-called Western classical musics [a term whose presumed generality is in fact misleading : see Tagg (1985) and Ling (1987)], while the lower ones are assigned to popular musics, folk musics and so-called ethnic musics. On the other hand, such a view implies the establishment of two sets of musical attributes: a) primary attributes, presumably "staples," which are maintained separately from music theory (and borrowed from acoustics), and which as a consequence refer to the musical object itself, allowing it to grasp its most intrinsic "qualities"; b) secondary attributes, relative both in time and space, which designate those properties that relate to the action or involvement of the subject in the musical object. Needless to say, the latter is the exclusive realm of the socalled musical context, as well as of music's psychological, cultural and political aspects. These secondary attributes are thus considered as subsidiary if not inessential elements in defining music itself.

Contrary to conventional wisdom, the hierarchic definition of music is not the exclusive preserve of orthodox musicological theories. It is the preserve also of many modern and valued social scientific discourses. For instance, despite its well-known socio-cultural orientation, Lévi-Strauss' approach to music provides a good example of hierarchic evaluation and separation. LéviStrauss claims that nature provides music with its genuine, everlasting and universal components, which he explicitly defines according to the physical properties of sonic objects; he adds that culture is thus responsible for the relative components of music, since it speaks to subjectively chosen sounds and sound combinations - choices which are the foundations of the variety of musical objects, practices and the rules of their combination (1964: 30). This nature/culture dichotomy reproduces, although in a slightly different form, the separation of primary and secondary attributes described above. It enables Lévi-Strauss to disqualify serial music and "musique concrète" as legitimate musical phenomena on the grounds that the "contemporary musical thought" they stem from "rejects, in a formal or tacit way, the hypothesis of a natural foundation which objectively justifies the system of fixed relations between the notes of the scale" (Ibid: 29).

This is only one example which illustrates how a theory that displays an explicit concern for music as a socio-cultural phenomenon can still lead to the hierarchic ranking of musical works and practices as the normative consequence of the objective, analytical and descriptive categories it brings 
into operation. By tending to encapsulate music's social character in secondary attributes - "dependant variables" in traditional terminology many social scientific frameworks reproduce the orthodox - if not autonomous - views they rightly mean to challenge. So, within the domain of "conceptualized art," music is defined in hierarchic terms. If the existence of social aspects is admitted, their influence tends to be considered as inessential to music's most determining and genuine characteristics. These theories do not deny the fact that music has, indeed, something to do with culture and society. However, they tend to assert that "music itself" can be defined without any further reference to social or cultural dimensions. Accordingly, it is assumed that the specificity of music lies exclusively in its sonic materiality (musical "notes" defined from an acoustical point of view), as well as in its aesthetic, if not formal, nature. In other words, its specificity could presumably be grasped regardless of any so-called "extra-musical" features since this specificity would rest in the musical object itself.

\section{“Cultural Product”: From Diversity to Difference}

This second conceptual field gathers together some of the most widely held views within the whole field of "contemporary" musical studies. In many respects, it constitutes the theoretical opposite of the "conceptualized art" concept, whose key assumptions it challenges. Its earliest developments can be traced back to the end of the Eighteenth Century, when the acoustical foundations thesis was first seriously criticized by theorists who rejected the presumably natural and universal character of music, insisting rather on the inexorable relativity (both in time and space) of musical phenomena. From then on, many have followed the same basic path, addressing music as an essentially cultural phenomenon.

Without pretending to summarize this extremely diversified univers de discours, I would like to give an overview of the semantic field of the concept of the "cultural product" by focusing on its fundamental common denominators. They can be said to represent the four central assumptions which draw together the majority of theories:

a) music is humanly organized sound (Blacking 1973); it is basically a human phenomenon which encompasses not only sounds and sound objects, but all individual as well as group behaviors, attitudes, practices and activities involved in their production and reception;

b) one should be concerned with musics, the plural designating the presumed intrinsically polymorphous character of music;

c) music is the result of practices and ideas acquired by human beings as members of a society; consequently, all criteria facilitating the description 
and evaluation of any music are necessarily relative to what each society or collectivity considers as music at a certain stage in its socio-historical development;

d) there exists an intrinsic relationship between music and culture, as musical sounds and practices in a given collectivity are relative to the respective social functions music carries out in any particular cultural setting.

These premises can be considered as the theoretical motivation of various analyses whose main concern is the study of music in its context. They concentrate on musics and musical events as they are experienced in realtime, keeping in mind the assumed functional relation between music and culture, which is a key to an accurate understanding of their respective characteristics. In this respect, two tendencies can be identified: some theorists assert that the basic function of music is to establish and ensure social order (Silbermann 1968), while others argue that it seeks to develop and increase the sense of belonging experienced by members of competing groups (social classes, and gendered, ethnic and linguistic groups) in a given community (Blacking 1973; Hebdige 1979).

Such a wide univers de discours is in no way homogeneous; in many respects it is a site where factions compete for power and influence. However, despite all conceptual and analytical discrepancies - otherwise crucial - it does display an intrinsic coherence. Such a theoreticalepistemological coherence derives from the fact that the above-mentioned assumptions converge towards a conception of music as both a medium and an expression of group differentiation. These discourses convey a differential approach to music, by which I mean that: a) they address music as one fundamental means by which groups (and individuals) actualize and manifest their respective cultural and social traits, and so their mutual differences; and b) in a formal or tacit way, they assume that these differences constitute crucial parameters since they provide each music with its most original characteristics. These characteristics act as determining components in the very definition of musical phenomena as cultural phenomena.

When examining socio-cultural theories, one cannot help but notice, on the one hand, their general concern for the variety of musical phenomena both synchronically and diachronically - whether this variety be studied at the level of sound products, or of production and reception practices; and, on the other hand, their tendency to address this variety as something ascribable to the no less varying socio-cultural contexts in which these musical phenomena prevail. This entitles us to think that musical diversity is the key issue, if not the implicit object of analysis. However, this diversity is not discussed first and foremost in terms of the musical "causes" which could account for it - an approach devotees of the "conceptualized art" concept 
would probably be inclined to follow. Diversity is rather conceived as having, above all, (socio)cultural origins, and so tends to be theoretically constructed as difference.

In the light of this coherence, revolving around the issue of diversity, it is possible to grasp the full implications of this concept of music. We have already discussed the meaning of the basic assumptions of this "cultural product" approach as the "study of music in its context." I would argue that this expression is more than a general descriptive statement, and that the very notion of context constitutes a key procedural framework. Methodologically speaking - that is, from the point of view of the articulation of the empirical object of research to its theoretical construction - the framework allows for movement:

FROM: the acknowledgement of the particularities of both musical and cultural phenomena in a given setting

TO: the recognition of their inter-dependence;

FROM: this account of inter-dependence

TO: the definition of the relativity which explains it;

FROM: the establishment of the relativity of music and culture

TO: the construction of music as a medium and expression of difference.

Within "contemporary" theory, this process leads to two main definitions of music as difference. Both will be examined briefly in order to give a more substantial idea of the meanings assigned to the notion of difference in relation to music. The first one, which I call the generalization mode, is based on the acknowledgement of culturally distinctive musical phenomena which, in one way or another, are compared in order to disclose their potential similarities. Once these similarities have been identified, a (regional or global) theoretical model can be elaborated which should, in principle, explain the characteristics of the musical phenomenon under study from the point of view of the common traits it presumably shares with other musical phenomena.

Merriam's interpretation of the cluster theory is a good illustration of this process of theory construction. Being concerned mostly with diachronic diversity, his analytical strategy consists in regrouping musical cultures on relatively small scales, based on the musical traits they share (such as the instruments that are used), and the historic affiliations that existed between these cultural groups (as acknowledged by members of those communities). Merriam claims that it is possible to locate the original form of a given musical phenomenon and follow its further developments, starting from the centre of its diffusion (cluster) as thus identified. He argues that there exists only a few basic cultural and musical models (the most ancient ones) which 
change but slowly, and that through these changes there still exist close relations between "new" musical cultures and the original models from which they stem. Merriam thus concludes:

This does not mean that music does not change; it does change but with the exception of cultural accident, it changes within what seems to be a culturally determined framework. In other words, barring unusual exception, we can expect music over time to retain its general characteristics, and this is borne out in studies, for example, of New World Negro cultures whose music differs from the original African but retains what seem to be the characterizing traits of African music. (Merriam 1978: 297, my italics)

This example demonstrates how it is assumed that there exists a general (if not transcendent) mold from which singular musics or musical practices somehow derive, the latter being considered as more or less exact replicas of that mold. It can thus be said that within this type of framework, similarity does overcome diversity: despite their obvious differences, music and musical cultures share common traits, if not the same basic elements, origins and meanings.

In the case of the second process, which I have called the totalization mode, the very existence of a general mold is rejected. This does not mean that case by case inquiry remains the only viable strategy. But it does imply that no generalization should be drawn at the expense of the singularity (if not specificity) of musical phenomena, the underlying assumption being that "if it is possible to reach any generality, it is within difference itself that one can find it" (Pouillon 1971: 97). Accordingly, the totalization process also begins with musical phenomena in their respective contexts, but focuses on their dissimilarities; they are then compared in order to discover the constants that these organized systems of difference display. Totalities can thus be constructed: they are abstract patterns of relations whose definition rests upon the identification of the relations and contradictions which could account for empirical diversity, while explaining it both historically and structurally.

It is possible to illustrate the modalities of this construction by considering the approach developed by Cutler (1985) in his analysis of popular music. His starting point is a repudiation of the idea that popular music is homogeneous and wholly standardized: "so many commentators," he claims, "persistently confuse pop, popular and rock musics with folk musics, equally unable to identify correctly the irreconcilable differences between them or the nature and limits of their particular similarities" (Ibid: 30, my italics). He suggests that theorists concentrate on the qualitative, distinctive properties of those musics he assumes to be related to their respective conditions of production, reception and circulation, and to the "expressive needs" of the identifiable social groups, classes or communities they objectively manifest. 
Cutler distinguishes three archetypal musical modes - folk, classical and electronic - each one being the historical product of the dialectical combination of internal (having to do with phenomena such as instruments and musical languages) and external (having to do with phenomena such as ideology) relations of production. Trying to discover the "laws" which govern the development of music in specific cultural and historical contexts, he places a strong emphasis on differences, questioning his own model from this very angle. He asks, for instance, "what are the innate qualities of the mode of recording [electronic mode] which distinguish it from notation [classical mode] as a productive source of music?' (Ibid: 142), assuming that those qualities account for the diverse musical phenomena of which they are active components of production, reception and circulation.

This example shows how, in this kind of framework, it is assumed that musical phenomena possess a global and immanent coherence which is bound to be of a socio-cultural nature and which can only be grasped by and through their differences. If a global model is to be drawn, it cannot be reduced to a mere descriptive model; neither can it rest on presumed similarities, because in doing so, it will run the risk of denying the diversity it seeks to explain. It has to be constructed as an immanent comprehensive totality which can inform our perception of musical diversity while explaining it from the inside, providing the rules according to which the differences that account for this diversity appear as an organized (nonaccidental, non-arbitrary) entity.

In the end, these two modes convey divergent notions of difference. Within the generalization mode, difference is equatable with particularity, i.e. a particular phenomenon is but one of many possible actualizations of a general mold. According to the totalization mode, difference means difference as process ("alterité"), i.e., each phenomenon is inexorably singular, since it possesses an irreconcilable immanent difference. However, both modes share the assumption that culture constitutes the key to music and its undeniable heterogeneity, as music is defined - although in contrasting manners - not only as the result of acquired attitudes and practices but also as one of culture's very mode of production. In contrast to the "conceptualized art" concept, culture is not reduced to secondary attributes influencing music "from the outside"; at least in principle, it is considered to be an active component which takes part "from the inside" in the production and reception of music.

Together with its concern for diversity and for the construction of diversity as difference, this idea of culture informing music "from the inside" undoubtedly constitutes the most fruitful and interesting argument of the music-as-cultural-product approach. However, it still leaves unanswered some important questions, concerning especially the relation between culture and 
society and, consequently, music and society (culture acting as the intermediary term). Ambiguities arise because some socio-cultural theories (Merriam's for example) tend to reintroduce a kind of hierarchy: culture is established as the primary level, the site of all genuinely human aspects of collective life, as opposed to society, which is implicitly reduced to the secondary level, conceived as that mere set of rules and institutions whose impact or effect on collective life are seen as negative and dehumanizing.

Others frameworks (such as Cutler's to a certain degree) face similar problems insofar as they tend to encapsulate culture and society in the wellknown superstructure/base dichotomy. In such cases culture is often viewed as the mere reflection of the society which determines it. Music is thus seen as a more or less accurate image of its so-called social conditions of production. A very pervasive view amongst sociologists, this "social conditions" thesis might give the impression of accurately conceptualising music (through culture) as a genuine social phenomenon. This impression is misleading. This conceptualisation leads in fact to a pure "sociologism," since it tends to establish far too direct, automatic and mechanistic a link between music, culture and society. Moreover, by maintaining music and society in a relation of exteriority, such a view not only implicitly suggests that social reality remains outside music, but that society "pre-exists" or exists outside, independent of music.

Needless to say, the "cultural product" concept displays many interesting features, especially its emphasis on contexts and practices. However, not only does it remain problematic with regard to the social status of music, but its implications concerning the specificity of music are also questionable. First, with few exceptions (the work of Blacking provides one example), far less attention is devoted to musical objects or sonic phenomena. Does this mean that they, too, are culturally determined; that music could be defined from the point of view of the culture from which it stems, regardless of its sonic dimensions; that the context can be considered at the expense of the actual sounds its analysis conceals? Second, if the cultural foundations of music are undeniable, the "cultural product" concept cannot provide sufficient analyses of music's specificity. For, in terms of its premises, what would differentiate music from any other cultural phenomenon in a given society; or from any other social phenomenon as it is bound to be culturally mediated? Thirdly, if the specificity of music rests solely in its social conditions of production or practice, how could one explain that some musics do overcome their original, presumably specific, social conditions of practice or production? How could it account for what Wallis and Malm (1984) have called transnational musics? Once again, would it mean that one could only identify those "social conditions" outside music, thus grasping the basic components of society without further consideration for musical phenomena themselves? 


\section{“Symbolic Phenomenon": Towards a Generic Approach to Music}

The univers de discours of music as a "symbolic system" was first developed and institutionally recognized some thirty years ago. Its emergence did not pass unnoticed, occasioning controversies which have lasted to the present day. Even if some of its basic theoretical assumptions had already been discussed at the end of the last century by Simmel, Weber, Cassirer and others, this third concept of the tripartite division can nonetheless be considered as the most recent child of musical studies - and at least as one of the most significant.

The interest it arouses can be imputed largely to the main line of questioning it follows: while the "conceptualized art" concept is devoted mainly to the study of the musical object (musical structures), and while the "cultural product" concept focuses primarily on musical practices in their contexts, this concept seeks to explain the relation that necessarily exists between the so-called object, its mode of production, reception and circulation, and its context. In other words, this approach can be said to establish a bridge between the two previous conceptual fields. It addresses questions they left unanswered by using and combining some of the most fruitful notions and arguments they put forward. Such a combination might seem problematic since the previous concepts convey different if not contradictory approaches to understanding music. However, this contradiction does not arise because, in being more than just a plain "collage" of the "conceptualized art" and "cultural product" concepts, it provides a genuine synthesis of the two through a distinct definition of music as a symbolic phenomenon.

Considering the relative novelty of the field, it is understandable that no fully integrated synthesis has yet been achieved. As I have already mentioned, contrasting theories coexist which show but few common traits, divergences of opinion being even more striking than they were within the previous conceptual fields. Nevertheless, theorists seem to have reached some (implicit) agreements which the following assumptions should reflect:

a) music is a symbolic system insofar as musical structures can be considered as references, interpretations or reflections of individual and social experiences which are not necessarily of a solely musical nature;

b) music implies and supports a relation to human experience, i.e., to any moment experienced as a totality by an individual or a group of individuals forming a collectivity;

c) this relation ("renvoi") is of a non-referential nature, as music neither primarily nor essentially refers outside itself to objects and ideas. 
The previous assumption does not imply that music is symbolically selfcontained; on the contrary:

d) while musical structures should not be considered as meaningful in themselves, musical symbolism should not be reduced to a purely arbitrary or any other form of "conventional" signification.

These assumptions clearly indicate that the relationship between sounding objects and socio-cultural practices - considered as the two inextricable dimensions constitutive of music - is thus the prior concern within this conceptual field. Accordingly, the issues that are more frequently addressed and more fiercely debated are those related to the very object of this relation on the one hand, and its procedural modalities on the other hand. Let me give an overview of the semantic content of this concept by examining briefly the arguments involved in discussions over the "object."

One important question researchers are addressing is how to substantiate the experience to which music refers. Two main and opposing answers draw the most attention: a) since music is the object of individual investment, it refers to an experience of a subjective and mostly unconscious nature (Court 1976; Imberty 1979); and b) since music implies an objectification of social realities and meanings, it would refer first and foremost to an experience related to the social world. It is worth mentioning that the interdependence of these "levels of reality" is usually taken into account by proponents of either view. However, if both sides admit music is relevant to psychological as well as social realities, then why are those views considered divergent or contradictory? Is the debate reducible simply to an opposition between the philosophical traditions from which they respectively stem?

Their underlying philosophical premises are indeed relevant, but so are their respective definitions of "symbol," which seem even more determining. Those who claim the object of music to be related to inner worlds tend to assert that while signs are the foundation of cognition, symbols provide grounds for expressivity. According to Imberty (1979) they enable people to put aside the overwhelming presence of the external world and of rational thinking (both concerned with the object and its environment) in favour of a more emotive and truly aesthetic experience focused on the subject and their desires. Others who argue the object of music belongs to outer worlds tend to define symbols as mediations through which reality is socially constructed. Shepherd (1979), who supports this view, claims that all symbols imply an articulation of the material world: therefore, their respective "materiality" accounts for differences between various types of symbols (and between symbols and signs), and for the varying degree to which they objectify social relations. There is not the space to discuss in full 
the implications of both definitions; however, I would like to point out the main issues at stake here. They question the very nature of symbolism and knowledge, an issue which still tends to be approached with reference to language, although in different ways. In this respect, at least as far as their implications with regard to music as a social phenomenon are concerned, each definition is worth our attention, for both give rise to some interesting arguments.

The first definition of symbolism confronts knowledge with aesthetics in terms of the well-known subject/object opposition, hereby made equatable with a desire/reality dichotomy. For instance, according to Imberty, knowledge resides in signs and leads to an objective experience of the outside world, whereas art resides in symbols and enables only an emotive investment in the outer world. His theory conveys an approach to knowledge that can be characterised as positivistic (at least to a certain degree), as the approach defines knowledge as the unique and absolute realm of truth and facts. Moreover, the approach tends to place language in a position of superiority insofar as it defines language as the only possible way of designating facts, and so as the only reliable vehicle for knowledge. This entitles Imberty to claim that as a symbolic phenomenon, each musical work is "a communication of a way of feeling, seeing, interpreting that the artist suggests to other men [sic], hoping they will perceive part of his intentions" (Ibid: xii). However, this communication presumably has no relevance outside the realm of human subjectivity: music is but a "challenge" to reality, a form of "substituted satisfaction"' (Ibid: 35 ).

One of the most interesting aspects of this approach is that it asserts the existence of various symbolic forms, based on corresponding modes of symbolism. Not only can this approach facilitate the study of the so-called "symbolic function" with regard to its respective characteristics (relative to its uses in various symbolic phenomena and processes); it could also provide basic arguments which in turn could lead to the disclosure of music's specificity as a symbolic phenomenon. However, it also conveys arguments which are highly questionable. One of its limits is obvious: it introduces far too sharp a split between the inner and outer worlds, an opposition which seems to withdraw all subjectively experienced, individual or collective "events" from the domain of reality per se. Symbolism is thus reduced to being a subjective substitute for an objective but "unsatisfactory" reality! Does this mean that music would have nothing to do with "the real world," that it would merely provide an imaginary "pill" against boredom and alienation? In this respect, the second approach seems more fruitful since it implies that music is an active component of reality, contributing to its very production.

This definition of knowledge, which is the foundation of the second view, is 
based on the assumption that reality is not "given," but socially constructed through symbols: knowledge can therefore be said to be a social process constitutive of reality and its production. For example, Shepherd argues: "the reality specific to any group or society is collectively constructed by the people of that group or society through the mediation by words and other symbols of the experiences those same people have undergone" (Ibid: 3). The role of symbols is thus crucial and can be qualified as that of "representing' to us the totally intangible, fluid and dynamic set of social relationships within which we live"' (Ibid: 5). Since music is both symbolic and forms an integral aspect of reality, it thus "forms an integral aspect of that group or society's social construction of reality" (Ibid: 3). Since knowledge is being considered as a social process of the symbolic construction of reality and not as a quasi-objective state, it can be approached outside the realm of the true/false opposition. Moreover, since symbols are mediations of this construction and since music is undoubtedly symbolic, the latter can be said to fully participate in the production of social reality - not just as a subjective exponent of or substitute for reality, but as an active, if not necessary, component.

However, if it goes beyond the rather mechanistic distinction between objective and subjective realities, this approach implies a continuity between all forms of symbolism which, I believe, is misleading. In Shepherd's theory for instance, even though the existence of different symbolic phenomena is acknowledged, all symbols nevertheless involve the same type of mediation: an objectification of social relationships, which differs only in degree, not in kind. In my opinion, objectification is but one mode of symbolic mediation or "re-presentation"; although it might be especially adequate for describing and analyzing linguistically oriented symbolic phenomena, this is not sufficient enough a reason to use it as the criteria against which all symbolic processes can ultimately be defined and judged, not even when the comparison is of a negative order for language.

Most analysts would agree that there is as yet no unified semiological science. As the previous discussion illustrates, the same situation applies to the study of music as a form of symbolism. It might be a little early to draw any conclusions as to common theoretical standpoints or methodological strategies. Lots of questions are still receiving answers that are far from unanimously accepted. However, I think a focal point can be identified: a zone of convergence is becoming increasingly clear. Once again, this focal point refers to music's social character and the way in which it is addressed.

As a hypothesis, I would argue that theories constitutive of the "symbolic system" concept share a very similar approach towards understanding musical phenomena insofar as they tend to convey what I call a "generic" definition of music. By "generic" I mean a definition that infers the general 
properties that would belong to the logical comprehension of music as a genre. This concept of music stands as a meta-category, for it does not refer immediately to empirical phenomena but focuses on their constitutive integrating processes. In other words, when addressing "music," proponents of this view do not refer primarily to audible or conceptualized sounds; neither do they refer strictly to practices of production and reception; rather, they consider the abstract universe these sounds and practices form, the common underlying properties of the symbolic processes which provides them with their respective qualities as musical sounds and practices.

On a methodological and epistemological level, this definition displays original characteristics with regard to the other definitions previously discussed. It rests on what Ramognino (1972) calls "breaking techniques" (techniques de rupture), since it implies a shift in the process of conceptualization. From the identification of the empirical properties of given phenomena (empirical object), to the construction of the theoretical properties which define them as symbolic musical phenomena (theoretical object), there is no direct continuity. What, following Granger (1973), we can call semantic concepts (which refer more or less directly to observable dimensions of a phenomenon) are combined by syntactical concepts; these concepts are concerned with relations and patterns of relations, and therefore articulate semantic concepts and redefine them accordingly. In this case, the very notion of "symbolic system" is the key syntactical concept. Not only does it allow the articulation of musical structures, practices and contexts semantic concepts - it redefines them in the light of this articulation. Therefore, structures lose the autonomy and the prescriptive character they were granted within the "conceptualized art" concept; practices that helped distinguish music cultures within the "cultural product" concept are themselves differentiated according to the respective modalities of production and reception of the above-mentioned structures; finally contexts, which tended to be equated with culture as a whole in socio-culturalist theories, designate individual and social experiences - no privilege being attributed to culture at the expense of history, society or politics.

This generic definition is perfectly compatible with the construction of music as a fully-fledged social phenomenon. Indeed, music is (or can be) considered as intrinsically social, not only because it is a part of society and is influenced by it; not only because it shapes and is shaped by the culture in which it exists; but because, as a symbolic phenomenon, it participates and contributes fully in the social construction of reality. Once again, the "shift" is crucial: the social character of music is not reducible to any of its observable properties as such, but is related to the very nature of social reality itself, comprehensively defined as symbolically constructed and 
constituted. However, if the "symbolic system" concept tends to grant music a full social status, no generic definition has yet been able to account properly for its specificity.

The most advanced theories restrict this specificity to that of a "relative autonomy." Such a line of argument, developed by sociologists of art, is described by Janet Wolf:

although art is a social product (which is, however, thanks to the historical separation of the aesthetics as a distinct sphere, regarded and experienced as remote from its social determinants) it is also the case that it is not simply a reflection of its social origins ... The relative autonomy of art and culture consists in the specific codes and conventions of artistic representation, which mediate and (re)produce ideology in aesthetic forms. (Wolf 1983: 88).

This line of thinking implies that the specificity of music rests in its symbolic or signifying nature, its own internal forms, relations and "structurations"; one would thus have to investigate the way in which musical devices transform and represent thought and ideology and infer, on this basis, music's specificity.

Despite its tendency to lean towards straightforward formalist semiology, this notion of specificity constitutes a valuable development when compared to approaches claiming the existence of an objective aesthetics, and to those asserting the complete isolation of music (and art) from practical activities and from the rest of social life. It must be said (to its credit) that it urges an investigation of the issue of specificity from an historical perspective, whether applied to music or any other symbolic phenomena. It also rejects the existence of universalistic features conceived from an absolute standpoint, excepting that of possible general characteristics on the level of historically relative social and symbolic processes.

Some analysts believe that this is one of the few theories which manages to keep its distance from the traditional superstructure/infrastructure model. This is the case insofar as the validity of the "reflection" argument is strongly repudiated. However, I would argue that the epistemological distance it has taken from this model is not as great as it might seem. For within the "symbolic phenomenon" approach (where this relative autonomy argument is most often favoured), there still exists an implicit tendency to reproduce the traditional model - a tendency which constitutes, in my opinion, a hindrance to an accurate understanding of the specificity of art forms in general, and of music especially.

In this case, the dichotomy takes the form of an opposition between symbolic and non-symbolic phenomenon. As previously mentioned, music is considered to be the symbol of something else, whether it be mental 
structures, unconscious desires, social relations, or the structures of group or social classes. Does that imply that what is musically symbolized is not symbolic; that social relations, for instance, are not also symbolically constituted? I consider this to be symptomatic of a view which tends to reduce symbolism to a mere theory of representation, thereby conceiving symbolism as a one-way process leading to a plain reproduction of socialpsychological realities. In this respect, the only difference from the superstructure/base model (which is not that significant) is that instead of a pure reflection, symbolism implies a representation according to the particular devices put into motion by a given symbolic form. Does music represent in a sonic form what literature, for example, re-presents in textual forms, both being merely another "picture" of the same basic reality?

The main impediment or problem is how to address symbolism as an intrinsic and constitutive dimension of reality in general, as well as an integral component of musical or any other artistic phenomenon. Within the "symbolic system" concept, much energy is devoted to the analysis of the relationships between musical objects, practices and contexts - and their value should not be neglected. However, the correlative but difficult and complex questions that concern the relationship between musical symbolism and symbolism in general, and those between symbolism and reality, are still disregarded: the question remains: "how can symbolism be articulated to a totality, whether the precise problem is that of the articulation of one level of reality or that of a particular point of view?' (Ramognino, 1982: 85). As long as this issue is not dealt with explicitly, music will still be regarded as some sort of psychological or social exponent; society (whatever is meant by that) will still be conceived as primary and music, secondary; and the acknowledgement of music's specificity will be reduced to the acknowledgement that codes and conventions of artistic representation contribute to the reproduction of society and culture in an aesthetic form which attests to music's relative autonomy.

\section{BY WAY OF CONCLUSION: A WORKING HYPOTHESIS}

I commenced this exposé by claiming that sociology could make a significant contribution to musical studies by putting forward a definition of music as a fully-fledged and specific social phenomenon. This paper will have achieved its aims if the limits of contemporary discourses on music with regard to its social status have been clarified and if some of the basic arguments upon which further theoretical developments could eventually be based have been outlined.

These new if not original developments are bound to rely, at least in part, on already existing arguments. As suggested above, the concept of "symbolic system" seems, in this respect, the most fruitful one insofar as it does allow 
for an acknowledgement of the intrinsically social nature of music. However, it does have as many limits as the other univers de discours as far as grasping the specificity of music is concerned. I strongly support the fundamental standpoint of the generic definition which makes it possible to grasp the constitutive, symbolic character of music. But once again, I wish to stress the importance of dealing with symbolism as a constitutive component of reality, including music.

As futile as it might look, this small addition or re-orientation could well lead to a revised approach to the question of specificity, as it provides the theoretical foundations of a definition of music as a particular form of knowledge. This is the hypothesis I have come to develop and which guides my research: as a form of knowledge, music can be conceived as both an expression and mode of expression that not only reproduces social reality but also, and most importantly, contribute to its very production or creation. Moreover, the singularity of this form of knowledge might rest in the way music contributes to the construction of social time-spaces. Hence, as a symbolic process, music would take an active part in the production of those times and spaces which are the very foundations of societies in their irreducible originality.

At this point, an advantage of the "cultural products" concept can be turned to good account: namely, the idea of music as a medium of differentiation. It was argued that music either contributes to the development of people's sense of belonging (totalization mode) or to the development and reproduction of social order (generalization mode). However, both theses lead to the idea of music being reduced to the production of self-contained entities: some "we" that is constructed through conflict, or some "I" constructed through order. They do so because they tend to borrow implicitly or more formally from identity theories. I would suggest we develop a theory of difference in process ("alterité") which would articulate the two processes of construction that are unjustifiably opposed in socio-cultural theories. As it relates to music as a form of knowledge whose characteristics would arise from the fact that it implies the construction of times-spaces, a theory of difference in process would focus on: a) the process of similarity, i.e., the production of entities understood as "particular" in relation to the "general" mold of which they are socio-historically mediated actualizations and which explains them as distinct groups or societies; and b) the process of difference, i.e., the production of entities characterised as "singular" with regard to the "universal" scheme to which they belong in their own way and that explains them as a group or society in their own terms. This could enlighten how music in Québec, for example, contributes to the production of times and spaces and how Québecois musics play an active role in the ongoing production of the distinctiveness of Québec society, while at the same time being an integral part of the very production of Québec as a 
society, defining in and through music, its very foundations.

I do not intend to argue that music creates a parallel, self-contained reality but rather, that it definitively adds "something" to social reality as it is usually conceived, both a quantity and a quality that might not exist otherwise. In fact, I totally disagree with those sociologists who, like Dasilva, Blasi and Dees for instance, claim that: "The sociologist has little to contribute to music as music . . . the sociology of music is not about music but about society" (1984: 1). On the contrary, I believe it is time social scientists, sociologists in particular, stopped evading the issue of music, put an end to reducing musical issues to mere empirical questions, and ceased turning towards musicologists for answers to questions which, I would argue, are in some measure sociological ones. Not only do we have to be prepared to theorize music from a sociological (or a social scientific) point of view. We also have to do it knowing that music has more to tell us about society than society could tell us about music. For as Antoine Hennion has rightly said: "It is not up to sociology, to social relations as we know them, to come and explain to us the meaning (or non-meaning) of music, it is more up to music to reveal to us an unknown social world" (1981: 19).

\section{REFERENCES}

\section{BAUMAN, ZYGMUNT.}

1973: Culture as Praxis. London: Routledge and Kegan Paul.

BLACKING, JOHN.

1973: How Musical Is Man? Seattle: University of Washington Press.

1977: "L'homme producteur de musique », Musique en Jeu , 28: 54-67.

COURT, RAYMOND.

1976: Le musical: Essai sur les fondéments anthropologiques de l'art. Paris: Klincksiek.

CUTLER, CHRIS.

1985: File Under Popular. London: November Books.

DASILVA, F., BLASI, A. and D. DEES.

1984: The Sociology of Music. Indiana: University of Notre Dame Press.

GRANGER, G.-G.

1973: «L'explication dans les sciences sociales », Informations sur les sciences sociales, X: $31-44$.

HEBDIGE, DICK.

1979: Subculture: The Meaning of Style. London: Methuen.

HENNION, ANTOINE.

1981: Les professionels du disque. Paris: A.M. Metaillé. 
IMBERTY, MICHEL.

1979: Entendre la musique: sémantique psychologique de la musique. Paris: Donod.

LEVI-STRAUSS, CLAUDE.

1964: La cru et la cuit. Paris: Plon.

LING, JAN.

1987: Europas Musikhistoria, Tome 2. Unpublished Manuscript.

MERRIAM, ALAN P.

1978: The Anthropology of Music. Evanston: Northwestern University Press.

\section{NATTIEZ, JEAN-JACQUES.}

1987: Musicologie générale et sémiologie. Paris: Christian Bourgeois.

POUILLON, JEAN.

1971: « L'œuvre de Claude Lévi-Strauss » in Claude Lévi-Strauss (ed.), Race et histoire. Paris: Denoel-Gonthier: 88-130.

\section{RAMOGNINO, NICOLE.}

1982: «Pour une approche dialectique en sociologie », Sociologie et sociétés, 14: 83-96.

SHEPHERD, JOHN.

1979: "Music and Social Control: An Essay on the Sociology of Musical Knowledge," Catalyst, 13: 1-54.

1981: “Toward a Sociology of Musical Styles," Canadian University Music Review, 2: 114-137.

SHEPHERD, JOHN and GRAHAM VULLIAMY.

1983: "A Comparative Sociology of School Knowledge," British Journal of Sociology of Education, 4: 3-18.

SILBERMANN, ALPHONS.

1968: Les Principes de la sociologie de la musique. Paris: Droz.

TAGG, PHILIP.

1985: "La musicologie et la sémantique de la musique populaire ", Analytica, 47: 77-95.

WOLFF, JANET.

1983: Aesthetics and the Sociology of Art. London: Allen and Unwin. 